УДК 325; 327; 329

\title{
Владимир АВАТКОВ
}

Дарья ЯКИМОВА

\section{ОТНОШЕНИЯ ГЕРМАНИИ И ТУРЦИИ НА ФОНЕ МИГРАЦИОННОГО КРИЗИСА}

Статья поступила в редакцию 26.04.2019

\begin{abstract}
Аннотация. В статье исследуется влияние миграционного кризиса в Европе на взаимоотношения двух ключевых партнёров - Германии и Турции. На фоне проблем, порожденных наплывом просителей убежища, происходит секьюритизация международной миграции, пересмотр механизмов миграционной политики, приоритизация странами Евросоюза своих национальных интересов. Особое внимание уделено роли турецкой диаспоры во взаимоотношениях Берлина и Анкары. По результатам исследования представляется очевидным двойственный характер влияния миграционного кризиса на отношения двух стран как точки соприкосновения, так и камня преткновения в отношениях сторон, вынужденных искать прагматичные решения даже на фоне эмоциональной полемики и кризиса доверия.

Ключевые слова: беженцы, миграционный кризис, миграционная политика, Европейский союз, Турция, Германия, интеграция, диаспоры.
\end{abstract}

Противоречивый процесс глобализации до сих пор порождает многочисленные дискуссии относительно своей объективной и субъективной стороны, а также о пределах управляемости и о существовании такого феномена, как деглобализация [Громыко, 2018: 138-141]. Неоспоримо то, что этот процесс характеризуется усилением взаимозависимости национальных государств, беспрецедентными масштабами миграции. Помимо процессов глобализации, активизации миграционных потоков способствуют развитие современных технологий и средств коммуникации,

(ㄷ Аватков Владимир Алексеевич - к.полит.н., старший научный сотрудник ИМЭМО РАН им. Е.М. Примакова, доцент кафедры международных отношений Дипломатической академии МИД России. Адрес: Россия, Москва, ул. Профсоюзная, д. 23. E-mail: v.avatkov@gmail.com

(c) Якимова Дарья Александровна - младший научный сотрудник АНО “Центр востоковедных исследований, международных отношений и публичной дипломатии”. $\boldsymbol{A d -}$ pec: Россия, Москва, Дмитровское шоссе, д. 157, корп. 5. E-mail: daria.yakimova.da@gmail.com

DOI: http://dx.doi.org/10.15211/soveurope320205160 
наличие значительного числа конфликтов, увеличивающийся разрыв по линии Юг-Север, а также открытость границ в рамках отдельных интеграционных объединений [Надеждин, 2017: 38]. Особую значимость проблематике придаёт тот факт, что в результате войн, кризисов и геополитических трансформаций некоторые государства утрачивают способность осуществлять функции аппарата управления [Аватков, Каширина, 2017: 9], теряя контроль над процессами миграции.

\section{Миграционный кризис в ЕС}

Кумулятивный эффект целого ряда экономических и геополитических факторов вылился в беспрецедентный миграционный кризис 2015 г., ставший крупнейшей гуманитарной проблемой, с которой сталкивался Европейский союз за всю историю своего существования. В 2015 г. в странах Евросоюза были зарегистрированы $1255600^{1}$ соискателей убежища (преимущественно из Сирии, Ирака, Афганистана), зафиксировано 1,8 млн ${ }^{2}$ случаев нелегального пересечения границ ЕС.

В подобной ситуации отсутствие эффективной политики интеграции мигрантов порождает для любой страны-реципиента целый комплекс проблем, выражающийся в дестабилизации культурно-гетерогенных социумов и неприязненном отношении населения к приезжим. Согласно научным теориям, это может быть обосновано объективными (экономический конфликт интересов) или субъективными предпосылками (социально-культурный фактор, стереотипы, предрассудки). На практике эти противоречия дополняют и усиливают друг друга [Монусова, 2016: 58-59]. Происходят секьюритизация миграции, т.е. её корреляция с понятием угрозы и проблемой внутренней безопасности; социальные конфликты в связи с экономической и социальной нагрузкой; нивелирование способности государства контролировать границы, обеспечивать безопасность населения; нарушение культурной идентичности гетерогенных обществ, развитие межэтнических конфликтов [Маталаева, 2017: 45-50].

На этом фоне Европейский союз был вынужден переосмыслить механизмы борьбы с нелегальной миграцией и перейти к проактивной политике, подразумевающей рестриктивные и превентивные подходы. Одним из активных участников разработки новой политики стала Германия, которая, однако, столкнулась с рядом проблем как внутри ЕС - так называемый “кризис солидарности”, так и в отношениях с одним из важнейших партнёров по сдерживанию миграционных потоков Турцией.

\section{Миграционный вопрос внутри Германии}

Лидером по числу соискателей убежища в 2015 г. стала Федеративная Республика Германия, на чью долю пришлось более $1 / 3$ от общего числа заявлений по

\footnotetext{
${ }^{1}$ Asylum in the EU Member States // Eurostat. 2016. March 4. URL: https://ec.europa.eu/eurostat/documents/2995521/7203832/3-04032016-AP-EN.pdf/790eba01381c-4163-bcd2-a54959b99ed6 (дата обращения: 05.03 2019).

${ }^{2}$ Ibid.
} 
странам-членам ЕС (441 800 заявителей ${ }^{1}$, на 155\% выше показателей 2014 г. ${ }^{2}$ ). Благоприятная экономическая ситуация (уровень безработицы в 2 раза ниже, чем в среднем по Европейскому союзу ${ }^{3}$ ), культивируемое чувство ответственности за преступления Второй мировой войны, опыт взаимодействия с мигрантами из Турции и позитивные оценки большинства экспертов способствовали первоначально достаточно спокойному восприятию масштабной миграции [Квашнин и др., 2017: 98-99]. В СМИ суть самой проблемы освещалась довольно абстрактно. Не поднимались ни вопросы о роли Евросоюза в дестабилизации ситуации на Ближнем Востоке, ни о последствиях масштабной миграции для страны-реципиента [Нарочницкая, 2016: 31-32]. Экспертные и правительственные круги не учли, что миграция со временем размывает идентичность государства, меняет его внутриполитический ландшафт, подрывает межнациональное и межрелигиозное согласие [Федоров, 2016: 3-5].

Повсеместно наблюдается нежелание интегрироваться со стороны самих мигрантов и беженцев, сталкивающихся в инокультурном социуме с проблемой определения собственной идентичности. Последнее относится как к недавно прибывшим, так и мигрантам и их потомкам, проживающим на территории Германии на протяжении уже достаточно длительного времени.

Строгое следование собственным традициям и обычаям - это, с одной стороны, потенциальный конфликт с принимающим государством, а с другой - залог благосклонного отношения со стороны своей диаспоры, так как инокультурная среда укрепляет групповое этническое самосознание, усиливает роль субъективнопсихологической составляющей в целом. При этом этническая и религиозная разнородность мусульманских диаспор (отсутствие организации, представляющей интересы всего мусульманского населения) осложняет их взаимодействие с властями принимающего государства [Погорельская, 2008: 65-73]. Маргинализация мигрантов и беженцев приводит к их социальной изоляции, наблюдается тенденция к формированию “параллельных сообществ" и анклавов внутри государствреципиентов, что даёт плодородную почву для появления различных угроз, вплоть до “диаспорального терроризма" [Надеждин, 2017: 39].

Целый ряд кризисных явлений (усталость от несменяемости элит, неэффективность миграционной политики, серия терактов в европейских городах, растущее чувство несправедливости) способствует поляризации и радикализации общества страны приема мигрантов, росту популярности правых партий и движений. Новые политические силы предлагают простые, но достаточно жёсткие для либерального общества методы решения проблем - закрытие границ, приостановка приёма беженцев и т.д. [Надеждин, 2017: 43-46]. Их подходы находят отклик у части средне-

\footnotetext{
${ }^{1}$ Asylum statistics. Asylum applications (non-EU) in the EU-28 Member States, 2008-2018 // Eurostat. URL: http://ec.europa.eu/eurostat/statistics-explained/index.php/Asylum_statistics(дата обращения: 16.03.2019).

${ }^{2}$ Ibid.

3 Arbeitslosenquote des Euroraums bei 11,2 \% // Eurostat. 2015. March 2. URL: https://ec.europa.eu/eurostat/documents/2995521/6664120/3-02032015-AP-DE.pdf/0e4e0fdee78c-40b2-bbdb-fe617328820d (дата обращения: 20.03.2019).
} 
го класса, а также людей с высоким уровнем дохода (44 и 26\% соответственно) [Küpper и др., 2015: 49].

Чтобы не допустить дальнейшей радикализации общества, а также с учётом необходимости усилить меры безопасности правительство Германии было вынуждено со временем ужесточить свою позицию. Началась кампания по ограничению экономической миграции и депортации лиц, прибывших из стран, признанных безопасными для проживания (косовских мигрантов, албанцев и т.д.) [Зверева, 2015: 117-118]. Коалиционный договор между ХДС/ХСС и СДПГ от 7 февраля 2018 г. продемонстрировал ещё более жесткий подход. Договор фактически противопоставлял права мигрантов и беженцев правам местного населения, что обычно характерно для критикуемых правительством правых [Белов, 2018b: 2].

Таким образом, внутренняя обстановка в Германии побудила Берлин сыграть активную роль в продвижении вопросов сотрудничества с партнёрами Европейского союза по миграционной проблематике, прежде всего, со своим особым партнёром - Турцией, которая приняла на своей территории наибольшее число сирийских беженцев [Аватков и др., 2018: 135-140].

\section{Германия - Турция: партнёрство или кризис доверия}

18 марта 2016 г. на саммите ЕС - Турция было заключено соглашение, предусматривающее создание особого механизма обмена беженцами и мигрантами: все нелегально прибывшие в Грецию по Эгейскому морю мигранты подлежали реадмиссии в Турцию в обмен на равнозначное число зарегистрированных там сирийских беженцев. Предусмотрены: финансовая помощь в размере 6 млрд евро, отмена визового режима для турецких граждан (с условием выполнения 72 требований), активизация переговорного процесса о вступлении Турции в ЕС [Потемкина, 2016: 11-112].

Сделку подвергали жёсткой критике. В частности, в адрес руководства ЕС и правительства Германии звучали обвинения в готовности закрыть глаза на проблемы в области прав человека. Верховный комиссар $\mathrm{OOH}$ по делам беженцев подчеркнул, что соглашение о массовой высылке нарушает права беженцев. Human Rights Watch и Amnesty International заявили, что согласно Директиве EC 2013/32 Турция не может считаться безопасной страной, так как ввиду “географического исключения" к Конвенции ООН о статусе беженцев все неевропейцы претендуют на получение лишь временной защиты - статуса, который ограничивает права беженцев ${ }^{1}$. Кроме того, разногласия возникли в рядах самих государств-членов ЕС. Венгрия выступила против предоставления гражданам Турции безвизового режима.

${ }^{1}$ Q\&A: The EU-Turkey Deal on Migration and Refugees // Human Rights Watch. 2016. March 3. URL: https://www.hrw.org/news/2016/03/03/qa-euturkey-deal-migration-and-refugees; Say No To A Bad Deal With Turkey // Amnesty International. 2016. March 17. URL: https://www.amnesty.org/en/latest/news/2016/03/say-no-to-a-bad-deal-with-turkey/ (дата обращения: 26.032019). 
Кипр готов блокировать любое продвижение в переговорах о членстве Турции в ЕС. Подобную перспективу отверг и канцлер Австрии Себастьян Курц ${ }^{1}$.

Значительное влияние на партнёрство ЕС и Турции, а также степень эффективности подписанного соглашения оказали непростые взаимоотношения Берлина и Анкары, поскольку именно Германия определяет основные внешнеполитические приоритеты Европейского союза в отношении Турции [Белов, 2018а: 55]. Анкара занимает особое место во внешнеполитической стратегии ФРГ в связи с тесным экономическим сотрудничеством и наличием в стране крупной турецкой диаспоры. Те, кого в 1960-х гг. воспринимали как временных работников турецкого происхождения, на данный момент являются второй по численности этнической группой в стране (уступая лишь самим немцам). Большинство предпочитает говорить на родном языке, следовать собственным традициям и обычаям, формируя в немецких городах анклавы с автономным укладом жизни. Например, в Берлине (получившем название "Анкара на Шпрее”) турки составляют около 10\% населения: в районе Кройцберг, который нередко называют "Маленьким Стамбулом", доля населения турецкого происхождения превышает $40 \%$, а среди учащихся районных школ $70-90 \%$. Все эти факторы не способствуют успешной интеграции, что открывает окно возможностей для Анкары, позволяет ей оказывать влияние на турецкое сообщество Германии, тем самым продвигая свои интересы внутри ФРГ и во всём Евросоюзе.

Важнейшую роль в этом играет Управление по делам Турецкой Республики Диянет, ответственное за направление имамов и преподавателей турецкого языка в мусульманские общины Европы. При поддержке Диянет для наставления турецких общин Германии был создан Турецко-исламский союз по вопросам религии (ТИСВР) - один из главных выразителей взглядов турецкой диаспоры на территории ФРГ (его деятельность не раз вызывала неоднозначные оценки со стороны немецкого правительства) [Бибикова, 2014: 353-362]. Беспокойство вызывает и существование на территории Германии различных крайне радикальных пантюркистских организаций, таких как “Милли Герюс" и “Юлькючу” [Камкин, 2016: 4].

Тесные контакты политических элит Турции с диаспорами, а также их активное использование Анкарой в качестве инструмента "мягкой силы" не раз становились камнем преткновения во взаимоотношениях партнёров. Как правило, нарастание конфликтности следовало за внутренними трансформациями в Турецкой Республике либо за очередными противоречивыми высказываниями турецких политиков. К примеру, в 2008 г. в рамках своего официального визита в Германию Реджеп Тайип Эрдоган подчеркнул важность активного участия турецких мигрантов в немецкой политике, указывая на потенциал создания турецкого лобби, оказывающего влияние на внутриполитические и внешнеполитические решения ФРГ. Кроме того, он призвал турецкие общины всегда оставаться турками, поддержал нежелание интег-

${ }^{1}$ Exklusiv-Gespräch mit Ösi-Kanzler Kurz. So will er illegale Zuwanderung stoppen // Bild am Sonntag. 2017. Dezember 23. URL: http://www.bild.de/bildplus/politik/ausland/angelamerkel/soll-kanzlerin-bleiben-54290876,view=conversionToLogin.bild.html (дата обращения: 26.03.2019). 
рироваться, назвав ассимиляцию "преступлением против человечества"1 В 2011 г. на слова Ангелы Меркель о том, что речь идёт не о забвении этнической родины, а о важности интеграции, владении немецким языком и следовании немецким законам, Эрдоган обвинил канцлера в нежелании открывать турецкие гимназии и ненависти к Анкаре [Бибикова, 2014: 360-361]. Большой резонанс вызвали предвыборные митинги турецких политиков в городах Германии накануне президентских выборов в Турции в 2014 г.

Ещё больший негативный эффект возымели последующие события в Турецкой Республике, внутренняя социальная напряженность в Германии, усугубляемая наличием обширной и подконтрольной Анкаре турецкой диаспоры и проблемами с интеграцией вновь прибывших мигрантов и беженцев, а также разногласия по вопросам исполнения обязательств по соглашению 2016 г.

Период потепления в отношениях между партнёрами вылился в череду взаимных угроз и обвинений. Одним из поводов стала попытка военного переворота в Турции 16 июля 2016 г. и последовавшие за ней массовые аресты. Европейского союз заявил о нарушении принципов верховенства права и презумпции невиновности. Со своей стороны, Анкара обвинила Германию в укрывательстве предполагаемых организаторов переворота. Референдум от 16 апреля 2017 г. об изменении турецкой конституции и усилении президентской власти лишь усугубил кризис взаимного недоверия. Активная агитация политиков среди турецких общин в Европе встретила противодействие со стороны правительства Германии, запретившего проведение митингов и встреч с избирателями турецких чиновников [Szabo, 2018: 7]. Правительство Турции тут же заявило о "возрождении нацизма, ксенофобии и исламофобии" в ФРГ ${ }^{2}$. В преддверии выборов в Бундестаг в 2017 г. Эрдоган призвал турецкие диаспоры не голосовать за "врагов Турции" - партии ХДСХХCC, СДПГ и "Зелёные" [Белов, 2018а: 54], несмотря на то, что остальные партии настроены в отношении Турции ещё более критично. К примеру, представители партии “Левые" не скрывают своих симпатий к курдам, в частности к "Рабочей партии Курдистана" [Камкин, 2016: 3].

В январе 2018 г. президент Франции Э. Макрон открыто заявил об отсутствии перспектив в переговорах о вступлении Турции в Европейский союз ${ }^{3}$. Озвученная позиция во многом отражала мнение и Германии, наиболее близкого партнёра, которая не заинтересована в полноправном членстве Турции: численность населения позволила бы Анкаре претендовать на второе по размерам представительство (после Германии) в Европарламенте и других органах, определяющих стратегический

1 Erdogans Kölner Rede // Frankfurter Allgemeine. 2008. Februar 14. URL: https://www.faz.net/aktuell/politik/dokumentation-erdogans-koelner-rede-1511607.html (дата обращения: 27.03. 2019).

2 Если б я был султан: чем закончится схватка между Турцией и Европой // РИА Новости. 2017. 13 Марта. URL: https://ria.ru/20170313/1489848680.html?in=t (дата обращения: 27.03.2019).

3 Macron lehnt EU-Beitritt der Türkei vorerst ab // Deutsche Welle. 2018. Januar 5. URL: http:www.dw.com/de/macronlehnt-eu-beitritt-der-türkei-vorerst-ab/a-42045658 (дата обращения: 28.03. 2019). 
курс ЕС, что привело бы к изменениям в расстановке сил внутри объединения, ослаблению немецких и французских позиций [Бибикова, 2014: 360].

Открытие Турцией своих внешних границ с Евросоюзом ${ }^{1}$ на фоне обострения ситуации в сирийском Идлибе спровоцировало череду новых взаимных обвинений, характер которых с каждым разом становится всё более эмоциональным и раздраженным. Берлин не скрывает, что рассматривает все последние действия Турции в отношении мигрантов и беженцев как политический шантаж и рычаг давления на власти Германии. Однако, несмотря на требования ЕС выполнить миграционное соглашение в турецкой части в полном объёме ${ }^{2}$, Анкара продолжает настаивать на пересмотре его условий в более выгодном для себя ключе (требуя от Евросоюза расширения его финансовых обязательств). Согласится ли на это ЕС, во многом зависит от готовности Германии сделать очередной шаг к восстановлению доверия в отношениях с Турцией. Однако даже тогда под вопросом останутся долгосрочные перспективы достигнутого компромисса, а, следовательно, и продолжительность потепления во взаимоотношениях между странами.

Расширяющийся список взаимных претензий не позволяет говорить о европейских перспективах Турции в позитивном ключе. Можно констатировать, что даже в периоды спада напряжённости (многочисленные визиты на высшем уровне, заявления о нормализации отношений и т.д.) в повестке сохраняется немало острых тем, оказывающих исключительно негативное влияние как на сотрудничество Турции и Германии, так и на её сотрудничество с Евросоюзом в целом (с учётом определяющей роли Берлина в данном вопросе). В таких обстоятельствах сложно представить успешную реализацию миграционного соглашения даже потенциально, а имплементацию его отдельных аспектов - практически невозможно. Вступление Турции в ЕС осложняется всё новыми факторами. Европейская Комиссия настаивает, что Анкара не отвечает не только политическим, но и экономическим критериям [Altay, 2018: 179-185]. Кипрский конфликт, вопрос газовых месторождений вблизи Кипра, осуждение турецкой операции на территории Сирии, громкие заявления и угрозы Анкары дополняются такими раздражителями, как положения о “турецкой нации" в Конституции Турции, её антитеррористическое законодательство, вопрос смертной казни, проблема арестованных журналистов-граждан Германии. Возникает вопрос, заинтересована ли ещё Анкара в своём “европейском будущем”, и насколько оно отвечает её внешнеполитической парадигме и национальным интересам.

Миграционный кризис 2015 г. не только поставил вопрос об эффективности миграционной политики и единстве Европейского союза, но и вскрыл ряд внутренних

${ }^{1}$ Cumhurbaşkanı Erdoğan: 2 bin 100'den fazla rejim unsuru etkisiz hale getirildi // NTV HABER. 2020. February 29. URL: https://www.ntv.com.tr/turkiye/cumhurbaskani-erdogan2-bin-100denfazla-rejim-unsuru-etkisiz-hale-getirildi,vIyD8ZZ03kWMQlwdc3DYVg (дата обращения: 06.04.2020).

2 Statement on the situation at the EU's external borders // Council of the European Union. 2020. March 4. URL: https://www.consilium.europa.eu/en/press/press-releases/2020/03/04/statementon-the-situation-at-the-eus-external-borders/ (дата обращения: 06.04.2020).

Современная Европа, 2020, №3 
проблем, актуализировал необходимость проведения гибкой внешнеполитической линии. Ряд принятых национальных и наднациональных мер (введение системы квот, закрытие Балканского маршрута, усиление охраны границ, ужесточение внутренней миграционной политики, программы сотрудничества с третьими странами, соглашение по беженцам с Турцией и т.д.), а также улучшение ситуации в Сирии и Ираке привели к снижению числа новых прошений об убежище в Германии и других странах $\mathrm{EC}^{1}$. Однако говорить в полной мере о разрешении кризисной ситуации в Европе было бы преждевременно. Не решены проблемы эффективной интеграции прибывших мигрантов и радикализации обществ-реципиентов. "Новые механизмы" (“контролируемые центры”, соглашения о “вторичных перемещениях", создание "региональных платформ" в странах Африки) пока не смогли и вряд ли способны продемонстрировать реальные результаты, поскольку зависят от согласованности действий стран-членов и внешних партнёров Евросоюза.

В условиях глобализации миграционных потоков и усиления взаимозависимости государств решение проблемы миграционного кризиса (проблемы, которая имеет трансграничный характер) возможно лишь при условии сочетания эффективных внутренних мер с активизацией партнёрства со всеми заинтересованными внешними игроками. Германия не может допустить разрыва отношений с Турцией и аннулирования достигнутых договорённостей. У обеих сторон существует понимание безальтернативности сотрудничества. Ввиду объективных географических условий любой план Европейского союза по урегулированию кризиса, так или иначе, предполагает либо турецкое участие, либо полный отказ от политики “открытых дверей” и применение ещё более жёстких мер на внешних границах ЕС. Второй вариант способен спровоцировать развитие очередного гуманитарного кризиса у самых границ Евросоюза, разрешение которого с большой долей вероятности ляжет на его же плечи.

Несмотря на разногласия и непринятие внутриполитических трансформаций в Турции, Берлин стремится не допустить её дальнейшего отдаления. Об опасности изолированной и отчуждённой Турции на границах Евросоюза предостерёг ещё в 2016 г. бывший министр иностранных дел Германии Й. Фишер ${ }^{2}$. Кроме того, немецкое правительство попросту не может игнорировать факт существования в стране значительной турецкой диаспоры, а также того влияния, которое имеет на неё Анкара. Во взаимовыгодном партнёрстве заинтересована и сама Турция, так как ЕС является её главным инвестором и кредитором, не говоря уже о необходимости финансовой поддержки для содержания миллионов беженцев.

Можно констатировать, что миграционная проблематика оказывает двойственное влияние на партнёрство Германии и Турции. С одной стороны, она порождает дополнительные противоречия, а с другой, подталкивает стороны к более активному сотрудничеству. Вследствие этого, даже в условиях кризиса доверия, несмотря

${ }^{1}$ EU+ asylum trends - 2018 overview // The European Asylum Support Office (EASO). 2019. February, 13. URL: https://www.easo.europa.eu/sites/default/files/EASO-2018-EU-AsylumTrends-Overview.pdf (дата обращения: 31.03. 2019).

${ }^{2}$ Воробьёва Л.М. Германо-турецкие отношения вчера и сегодня // РИСИ. 2016. 16 Мая. URL: https://riss.ru/analitycs/30319/ (дата обращения: 31.03.2019). 
на агрессивную и обвинительную риторику, страны вынуждены искать приемлемые формы взаимодействия на основе прагматичного партнёрства. Свидетельством этого является тот факт, что каждый пик напряжённости во взаимоотношениях Берлина с Анкарой последовательно сменяется чередой двусторонних и многосторонних переговоров и попыток достигнуть пусть не долгосрочного, но взаимоприемлемого решения.

\section{Список литературы}

Аватков В.А., Каширина Т.В. (2017) Тенденции развития современных международных отношений. Научно-аналитический журнал Обозреватель-Observer, №11 (334).

Аватков В.А., Крылов Д.С., Сыртмач М.М., Якимова Д.А. (2018) Сирийский кризис беженцев. Проблемы вынужденного перемещения на Ближнем Востоке. Свободная мыслль. №6 (1672).

Белов В.Б. (2018а) Европейский вектор внешней политики коалиционного правительства ФРГ. Современная Европа. №4(83).

Белов В.Б. (2018b) Миграционный кризис в Германии и Евросоюзе - сложный поиск путей решения. Аналитическая записка №29 (125). Институт Европы РАН, Москва, Россия.

Бибикова О.П. (2014) Турецкие иммигранты в Германии: проблемы и перспективы. Ислам на Ближнем и Среднем Востоке. Институт востоковедения РАН, Москва, Россия, № 8.

Громыко Ал.А. (2018) Глобальный мир: риски и возможности. Современная Европа, №1.

Зверева Т.В. (2015) Миграционный кризис: “тихий развал” Евросоюза или новый этап в развитии интеграции? Вестник Дипломатической академии МИД России. Россия и мир. №4 (6).

Камкин А.К. (2016) Германо-турецкие отношения через призму миграционного кризиса. Аналитическая записка №27 (57). Институт Европы РАН, Москва, Россия.

Квашнин Ю.Д., Кузнецов А.В., Трофимова О.Е., Четверикова А.С. (2017) Миграционный кризис в ЕС: национальные ответы на общий вызов. Мировая экономика и международные отношения. Т. 61. № 1 .

Маталаева Ф.Э. (2017) Секьюритизация международной миграции в Европе. Научноаналитический журнал Обозреватель-Observer. №2(325).

Монусова Г.А. (2016) Восприятие иммигрантов европейским общественным мнением. Мировая экономика и международные отношения. Т. 60. № 11.

Надеждин А.Е. (2017) Внутриполитическая ситуация в Германии в условиях миграционного кризиса. Научно-аналитический журнал Обозреватель-Observer. №7(330).

Нарочницкая Е.А. (2016) “Кризис беженцев” и иммиграционный вопрос в Европе. Актуальные проблемы Европы. Сборник научных трудов, Москва, Россия, №4.

Погорельская С.В. (2008) Иммиграция и проблемы безопасности: на примере Германии. Актуальные проблемы Европы. Сборник научных трудов, Москва, Россия, № 4.

Потемкина О.Ю. (2016) Европейский Союз. Современная Европа, №2.

Федоров В.П. (2016) Пагубные действия Ангелы Меркель. Аналитическая записка №26 (56). Институт Европы РАН, Москва, Россия.

\section{References}

Altay, S. (2018), "Toward a "Privileged Partnership": The EU, Turkey and the Upgrade of the Customs Union”, Insight Turkey, vol. 20, no.3, pp. 179-198.

Avatkov V.A., Kashirina T.V. (2017) Tendencii razvitiya sovremennyh mezhdunarodnyh otnoshenij. Nauchno-analiticheskij zhurnal Obozrevatel'-Observer, №11 (334).

Avatkov V.A., Krylov D.S., Syrtmach M.M., Yakimova D.A. (2018) Sirijskij krizis bezhencev. Problemy vynuzhdennogo peremeshcheniya na Blizhnem Vostoke. Svobodnaya mysl'. №6 (1672).

Belov V.B. (2018a) Evropejskij vektor vneshnej politiki koalicionnogo pravitel'stva FRG. Sovremennaya Evropa. №4(83).

Belov V.B. (2018b) Migracionnyj krizis v Germanii i Evrosoyuze - slozhnyj poisk putej resheniya. Analiticheskaya zapiska №29 (125). Institut Evropy RAN, Moskva, Rossiya.

Современная Европа, 2020, №3 
Bibikova O.P. (2014) Tureckie immigranty v Germanii: problemy i perspektivy. Islam na Blizhnem $i$ Srednem Vostoke. Institut vostokovedeniya RAN, Moskva, Rossiya, № 8.

Fedorov V.P. (2016) Pagubnye dejstviya Angely Merkel'. Analiticheskaya zapiska №26 (56). Institut Evropy RAN, Moskva, Rossiya.

Gromyko Al.A. (2018) Global'nyj mir: riski i vozmozhnosti. Sovremennaya Evropa, №1.

Kamkin A.K. (2016) Germano-tureckie otnosheniya cherez prizmu migracionnogo krizisa. Analiticheskaya zapiska №27 (57). Institut Evropy RAN, Moskva, Rossiya.

Küpper, B. und Zick, A. (2015), "Zwischen Wut und Druck: Rechtspopulistische Einstellungen in der Mitte“, Wut, Verachtung, Abwertung. Rechtpopulismus in Deutschland, Verlag J.H.W. Dietz Nachf, CmbH, Bonn, Deutschland, pp. 44-60.

Kvashnin Yu.D., Kuznecov A.V., Trofimova O.E., CHetverikova A.S. (2017) Migracionnyj krizis v ES: nacional'nye otvety na obshchij vyzov. Mirovaya ekonomika i mezhdunarodnye otnosheniya. T. 61 . № 1.

Matalaeva F.E. (2017) Sek'yuritizaciya mezhdunarodnoj migracii v Evrope. Nauchno-analiticheskij zhurnal Obozrevatel'-Observer. №2(325).

Monusova G.A. (2016) Vospriyatie immigrantov evropejskim obshchestvennym mneniem. Mirovaya ekonomika i mezhdunarodnye otnosheniya. T. 60. № 11.

Nadezhdin A.E. (2017) Vnutripoliticheskaya situaciya v Germanii v usloviyah migracionnogo krizisa. Nauchno-analiticheskij zhurnal Obozrevatel'-Observer. №7(330).

Narochnickaya E.A. (2016) "Krizis bezhencev" i immigracionnyj vopros v Evrope. Aktual'nye problemy Evropy. Sbornik nauchnyh trudov, Moskva, Rossiya, №4.

Pogorel'skaya S.V. (2008) Immigraciya i problemy bezopasnosti: na primere Germanii. Aktual'nye problemy Evropy. Sbornik nauchnyh trudov, Moskva, Rossiya, № 4.

Potemkina O.YU. (2016) Evropejskij Soyuz. Sovremennaya Evropa, №2.

Zvereva T.V. (2015) Migracionnyj krizis: "tihij razval" Evrosoyuza ili novyj etap v razvitii integracii? Vestnik Diplomaticheskoj akademii MID Rossii. Rossiya i mir. №4 (6).

\section{Relations between Germany and Turkey in the Context of the Migration Crisis}

Received 26.04.2019

Authors: Avatkov V., Candidate of Science (Politics), Senior Researcher IMEMO RAS, associate professor Diplomatic Academy MFA Russia. Address: 23 Profsoyuznaya Str, Moscow, Russia. E-mail: v.avatkov@gmail.com

Yakimova D., Junior Research Scientist at the Center for Oriental Studies, International Relations and Public Diplomacy. Address: 157 Dmitrovskoe road, Moscow, Russia. E-mail: daria.yakimova.da@gmail.com

Abstract. The article explores the migration crisis in Europe, its impact on the relationship between two key partners - Germany and Turkey. Against the backdrop of the problems caused by the migration crisis, the securitization of international migration is taking place. The tendency of national interests' prioritization among the EU Member States impeded the EU migration policy revision. The author provides insight into the evolution of the migration issue in Germany. In the context of the migration crisis, special attention is paid to the Germany-Turkish partnership, the role of the Turkish Diaspora in the relations between Berlin and Ankara. The author argues that the migration crisis had a dual impact on the bilateral relations resulting both in overlapping interests and in points of discord. Has countries are forced to search for pragmatic solutions even in the face of the emotional disputes and a crisis of trust.

Keywords: refugees, migration crisis, migration policy, European Union, Turkey, Germany, integration, diaspora.

DOI: http://dx.doi.org/10.15211/soveurope320205160 